\title{
Something More and Something Else: Language as Excess and Material [3]
}

\author{
Daniela Cascella [1] \\ 31 March 2017 [2]
}

In this essay [4], I will consider my activities through writing and with writing [5] as a case study [6] to expose the necessary coexistence of research and specific literary procedures [7]. I will do so by outlining a type of researchinto-writing/writing-into-research [8] that employs language as excess and material [9] —an approach generated by a number of reflections and writing gestures through the work of other writers and poets (Clarice Lispector [10], Bhanu Kapil [11], Alejandra Pizarnik [12] among others) and shaped by writing in English as a second language; writing as a stranger in a language [13].

I will also discuss my role as a writing tutor in an art school [14], along with the generative implications of teaching writing through poetry, "ultra-translation" (Antena), "trancelation" [15], and hybrid forms [16]. The essay will reflect on forms of embedded reflexivity enabled by listening, which become active motors and materials of research, rather than fixed tools of presentation [17].

\section{$[1]$}

I write this:

- $\quad$ as a writer - not a theorist, not an academic;

- $\quad$ as a writing tutor - not a theory teacher - in a Fine Art MA, who supervises the final text submission in which students are expected to reflect and to reflect on their research and work;

- $\quad$ as an Italian writing in English as her second (or third, or fourth, if you count a dialect or two) language: displacing, deranging writing and selves as a stranger, displaced and deranged in a language;

- as a writer who inhabits literature as a transmission of materials drawn from music, sound, visual art, film, and literature;

- $\quad$ as a writer who never stopped listening. 
Imagine these pages are read to you, in an awkward acquired British accent which betrays Italian inflexions when caught unguarded in certain vowels and misplaced emphases. Imagine the sounded shape of these wordswritten, read, and heard - in a traffic between languages, in peripheries of sense. Imagine the sense of these words, never deadlocked in the confines of a discipline but sometimes, painfully, deadlocked in a definition of otherness externally enforced. Imagine a sense of writing never entirely aware of how words sound like- "groundless but not without ground," a writer once said.

"Groundless but not without ground," said Elfriede Jelinek in her 2004 Nobel prize speech, a forty-minute drift from the edges of literature and the excess of language, haunted by the spirits of Lord Chandos and Ingeborg Bachmann. ${ }^{1}$ I want to consider this groundlessness not without ground as the place of artistic research articulated and disarticulated through literature, its words unstable yet necessary, and to retain its discomfort and difficulty — not as a trophy to display, but as a prompt for enquiry and writing. Literature, I mean, away from purity, perfection, confinement: as tension, desire, imperfection, out of synch, ugly even.

This abstract was written in March 2017 at the end of a troublesome year: referendum, exclusions, unspoken omissions. It reflects the uncertainties experienced at the time as it demanded to embrace them, rather than set them aside. It demanded a statement of excess which would have otherwise been contained; it demanded to state that such excess puts pressure on language, and this is the space of literature. Sometimes, a form of an outburst of unease. A place for rebeginning. Sometimes a cadence, a rhythm, an arrangement, out of synch. A convulsion in stillness. [4]

On paper, the following words were put together intermittently between 21 August and 15 September 2017, in a relatively calmer period during which I revised other texts, prepared public readings, continued reading, and collecting thoughts into pages, not one excepting the other, one growing into the other. These words unfold out of a much longer timespan, which exceeds the timespan of the writing of this text, and of my life. Consider the interferences of different states of time, and of mind; the long stretches of time into writing, the moments of stillness, the thinking that goes into words, out of research and out of sorts, and in excess of words, "the meandering off a theme, the escape from 
a word and at once the hunt for words, their dismissal," which Fleur Jaeggy designated as "mental manners of writing."

\section{[3]}

"Something more and something else than words," wrote Alejandra Pizarnik to voice that form of maladjusted literature trickled from the pressures that being put on her writing. ${ }^{3}$ Hard to imagine the poet articulating 'research' as a confined activity, detached from writing, doing, life. Research, then: not between inverted commas, not in the capital, not pointed at but carried out-and carried very much within, shaped through marks as much as erasures, such as the small blackboard Pizarnik used to write on, day after day, and erased, sentence after sentence, and again, until only a handful of words would remain. Literature for artistic research likewise: doing as much as undoing, attention as much as waste, and wait, through writing. Adjusting the glance, and the ear: precisely.

I now realise I should have written, in the abstract, "language as writing as excess and material." The doing of writing embeds the research that exceeds it, and moves research into literature, no inverted commas marking their territory, rather: transits, traffics, pauses, erasures.

[4]

I began to write an essay-and this happened instead: an arrangement of tones, instructions, and summaries, outbreaks, echoes of selves, not all mine.

I want to tell you of a series of lectures Ingeborg Bachmann gave in Frankfurt in 1959-1960, which I read in an Italian translation by Vanda Perretta published by Adelphi as Letteratura come utopia ("Literature as Utopia"). Bachmann was militant and vocal against any form of fascism: not only the historical, but the types of fascism at home, in human relationships, and in the formal diktats of a discipline. And in the lectures she is uncomfortable with defining literature, placing her emphasis instead on poetics, and on a porous 
form of literature articulated in the doing of writing as a tension rather than an accomplished form-reflecting, although not explicitly, her own shift from acclaimed poetry to the untidy troubled prose of Malina and the constellation of frayed stories around it. For Bachmann, the only possible language against neat, perfect, closed formulations is "ugly language," which allows writing to continue being in spite of its incompleteness. I take Bachmann's ugly language to formulate literature-for-research as transmission and convulsion: an operation on words, an arrangement of systems of attuning and amplification, beyond polishing forms. This ugliness - and crucially, the discomfort in which it resides-lies in the doing and in the excess of writing, rather than being limited to what is read on paper. It has to do with its inflections and snags, with whom it encounters, how it sounds, where it is written from, what through and with - a necessary other in whichever form they might take: be it a dependable circle of readers, a specialist audience, an imaginary conference with the dead, or a broadcast across the ages. Research is in the attention, hours, and thoughts, imprinted on words as malleable, conductive materials to manipulate and arrange: not for closed and protected disciplines, but for undisciplined writing in motion. "What matters is to continue writing,"4 and, "Our enthusiasm for certain wonderful texts is, in fact, our desire for the blank, unwritten page." 5

Literature eludes any definition of research while embedding it in the viscosity of language as material. It is a movement which does not know its direction. It is a ghost, Bachmann (who wrote radio plays, and so did Jelinek) says in her lecture, her words channelling, in turn, those of Ernst Robert Curtius. It tends towards something other than itself, and it will never be perfection, rather, the embodiment of a "dream of expression which will never be fulfilled"6 and which is manifested, articulated, and complicated through ugly language. "We need to work hard with the ugly language which we inherited, to get to that language which has never ruled but which nonetheless rules our intuition and which we imitate ... and never fully grasp."7

And there is ground to this discomfortable being-writing, and a necessity to articulate it as such. For Bachmann literature is the glue between words and all that exceeds them, which allows what has already been shaped from within language to partake in what has not yet been told. "Our enthusiasm for certain wonderful texts is, in fact, the enthusiasm for the blank, as yet unwritten page, at which our future goals seem to be aimed." ${ }^{8}$ Crucially, she mentions

the impact of a thought that initially does not concern itself with any direction, which aims for knowledge and wants to construct knowledge with and through language. It is not about quality as such: it is about the 
awareness that you are in a trajectory, for life and death, which denies any casual word... The necessity of that pull and the ensuing direction is what matters. A unique and unrepeatable universe of words. There is no other choice. ${ }^{9}$

There is no other choice.

I had in mind Oliver Sacks, or: the transformation of neurological case studies into literature, utmost example of research as a material engagement with language. ${ }^{10}$

The 'theory' question.

From a faculty meeting a few years ago:

- 'And you could sign a new contract as a theory professor and supervise students' writing.'

- 'But I'm not a theorist: I'm a writer.'

I'm a writer, and I supervise students' writing in a university art department. I'd like to linger on this shift, from a model in which the theory professor is in charge of writing supervision in art schools, to a writer doing so-the shift in expectations, demands, models, procedures.

The acquired notion I encountered at this meeting, that teaching writing at an art school is possible only through theory, or if appended to a theory post, is not an insular issue, but a broader structural one. It touches on the way writing is perceived within the institution, and in turn by students. Too often writing is not seen as a complex work of doing and undoing, that engages with language as material and embodies many varied traffics with art-making, but simply as the host of some 'meaning' that clarifies and explains the work-as if the students' MA texts could miraculously emerge out of a series of abstract discussions and outlines. And too often in this context, the question of research in relation to writing is posed with regards to 'plans,' 'theories,' 'outcomes,' 'impact,' all generating misleading demands. Literature, by contrast, opens to 'groundlessness not without ground': it is a procedure that offers models and teaches how not what: not topics, but ways of tuning in, framing, assembling. Literature is not a fait accompli. 
The above does not mean that theory does not engage with language-but to state that there is not one privileged space, or context, or genre, or form where thinking happens: not exclusively in a seminar, not in the studio, not in theory texts. ${ }^{11}$ But in the doing of writing. Writing and reading, as forms of material engagement with language, require exposure to a range of models as wide as possible across cultures, genres and gender, canons and further out. This is not to say that writing is not invested in theories. But my work with the students is mostly concerned with how to shape a modus operandi in and out of a text. Neither is this solely about craft, but calls for constellations, contexts, references; and desires, models, access. The writing does not just happen as the spontaneous outpour of an art practice, or as a consequence of abstract plans. It has to do with what Jacques Rancière called "the long path of the dissimilar"12 — with what can only be encountered or set in motion through actual writing, not beforehand; through writing as action and as thinking with language; but also through reading as hosting writing; and through editing.

Following on from Bachmann, writing does not "happen," it is not "in the air." It takes shape in doing, and in milieus, that need to be at once found and set up: where do we harvest our words?

Which models are brought forward, which bibliographies, discographies, filmographies, exhibition histories, cultural frameworks are outlined in the context of a writing as research made and attended through language?

It's not about 'using your own words', but tuning in words, we inhabit and resonate and echo with, or exist in dissonance with, and take responsibility for: 'Language is never innocent.'13

[8]

See [7], and all that happens in the process by means of [9] to [17].

See [3].

[10]

A turning (tuning) moment in my understanding of writing and language as excess: watching Clarice Lispector's last interview, watching her sigh between words. ${ }^{14}$ The realisation that writing after Clarice could only begin for me in 
that gap, with that sigh, in that suspension: a presence beyond words, that punctuates them and inhales them. Nothing much could be said about it, but its fullness resounds and contains, porous, the pacing of intermissions, the breaking out of breath, on and off the page. It deforms and informs words in more words, not quite all hers, not quite all mine: writing is a gesture of friction, an act of small variance. It carves a space not ordered but heard: the space of a prolonged echo, like the sibilant hesitant echo at the end of 'Clarice's' if I try to pronounce it: can you hear it? Can you say it, 'Clarice's,' and perceive the friction in the simultaneous timing of echo? This is where writing as research begins: not to explain with definitions and limits, but to amplify, echo, transmit. Between the 's' of 'Clarice's' and the 's' that runs across 'silence'silence that holds excess in a transmission made of discrete instants and persistent through time. Writing is echoing, almost nothing, almost—so language and being, literature and research: "So writing is the method of using the word as bait: the word fishing for whatever is not word. When this non-wordbetween the lines—-takes the bait, something has been written."

\section{[11]}

In times when writing seems lost, going back to Bhanu Kapil's words allows words to get even more lost, then rebegin:

"I wanted to write a book that was like lying down.

That took some time to write, that kept forgetting something, that took a diversion: from which it never returned."15

"To speak from my organs in a fiction without end ... Wrote: a sound or act that 'serves to halt, even as it exposes, the ceaseless dispersal of the text."'16

Because she writes that she had to eat charcoal instead of writing. Because there is writing that is body that is material that is air that is race riot that is tension that is a periphery that demands and undoes and forms a cadence, a syntax. And you never entirely hold it.

\section{[12]}

Pizarnik, see [3].

\section{[13]}

The enhanced attention to form when writing in a second or third language highlights the awareness of operating within language as material—of writing 
as artifice, of identity attuned through words. This has got nothing to do with the recurring cliché around writing to 'find your own voice': on the contrary, it prompts writing as tuning into many voices and considers how to allow more than one voice to coexist, which resonant frequencies to linger on, which types of dissonance to employ. Crucially, it has to do with listening and waiting, rather than constantly producing. Finding a sentence, making a note, arranging a rhythm on a page are instruments of research into writing which embraces incidents and interruptions. Consider Samuel Beckett, switching languages following a desire to impoverish his words: literature does not always have to coincide with plentiful productivity. It also demands stillness, erosion, and erasure, and all that is left in these procedures: or, what Craig Dworkin called "the inescapable residuum of recalcitrant physical matter left behind when certain inscriptions do not occur as expected."17

\section{[14]}

On the grounds of my work across a variety of formats and contexts, and writing in English as another language, I have developed an approach to teaching shaped from within an understanding of language as material and a commitment to editing, listening, and close reading, along with rigorous work on referencing systems and contextual study appropriate to each student's research area. In my work, writing often drifts towards other forms and becomes a speculative prompt towards what is not there: likewise, my teaching is articulated in the tension between the presence of words and what eludes them through other mediums. Research as writing by artists exists in this tension.

A Fine Art MA is not a Creative Writing or Critical Writing MA: the range of questions, desires, doubts, ambitions, and demands each art student holds for writing is wide, as is the way their research is shaped into words. Some of them are not comfortable with language as a medium, others have established forms of writing with different aims than those of the MA text, others question the function of writing or struggle with English as a second language, and others are keen readers yet have difficulty finding a shape to channel their research material.

Developing the MA text asks the students to place their research and work within a constellation of references that they must own, read in detail, arrange, and present. This can only happen when it is clear from the outset that they are to establish their writing as artists: such positioning is key in the development of their MA text. I support them by discussing writing as conversation and transmission rather than an outpour of explanations, by encouraging them to 
find a form which is never only 'on paper' but exists in the vicinity of their artmaking. The fact that each student can choose the form in which they wish to articulate their words is crucial. This form is not arbitrary: it demands that they set up a rigorous position from which they write, through sustained engagement with a textual practice and commitment to independent research in proximity to their final exhibition project. The text is not expected to be a display of knowledge: the question is how knowledge is transmitted and made through writing, how to hand over an array of research material in a way that is consistent and focused, in a form-best perhaps to call it a rhythmic arrangement - that is complex and precise, and that holds together.

Some key points in my teaching:

- Research, systems of references, literature review, and contextual analysis: these are effective springboards for students to begin and articulate a text that embeds at once a material engagement with language and critical/ contextual understanding, through independent research and evaluation of how to compile and work through bibliographies, discographies, filmographies, exhibition histories.

- Reading groups: writing is generated from reading, and in these groups, we read together and study examples drawn from experimental prose, poetry, conceptual writing, and writing by artists. In parallel, we discuss how artists can work through, echo, and transform the substance of a studio practice into language. Exposure to a wide range of writing styles is vital in opening up possibilities. We also analyse and highlight different purposes and demands, speeds and modes of production of writing; differentiating, for example, between the purposes of writing for performance, of writing notebooks as the chronicle of a practice, and of the MA text.

- Writing workshops: writing is generated from writing, as the students work with the materiality of text. So far my workshops have focused on constraints, residues, instructions, 'writing through,' listening, stuttering, rewriting, rhetoric devices, imaginary conversations: aiming to enable students to articulate and challenge their respective approaches to writing.

- Editorial work: I work with students in an editorial capacity through draft revisions and written comments ranging from structural to line edits, allowing them to establish a consistent style and approach. Their research question is sharpened from within the writing process, as they gradually understand that the MA text is a site of complexities which they can employ at large to find and offer yet another point of access to their practice.

- Necessary form and independent research: I work with students so that they can develop a form of writing for which there is no alternative. Its very specific form is born out of a rigorous and sustained engagement with their 
practice. It could not be done other than that way. This condition of 'no alternative' is not related to the idea of 'finding your voice,' too connected to notions of authenticity [13] —rather, it's a case of hearing the complex interplay of frequencies and intermissions within a research project, and what a student chooses to tune in for that specific project. Literature in this sense is presented as a transmission of material, rather than the production of singular, isolated, authorial gestures: not as an individual endeavour, but a collective one that cuts through time, tunes in a range of materials, searches for or establishes milieus.

- For those students whose first language is not English, the awareness of language as artifice and their sense of being strangers in a language are important tools to generate types of writing grounded on their systems, addressing insecurities by transforming perceived shortcomings into distinctive elements. Specific work on the heightened attention to form that exists when operating in a second language allows them to realise that writing is a signifying practice to be shaped from within the very making of it.

$[15]$

Three key terms that contribute to my teaching, and to speculative approaches to literature and research:

Poetry: "I should have written poetics." See [4] and [6].

Ultratranslation: defined by Antena as "messy, excessive unruly," ultratranslation is a way of being with words which takes the untranslatable as starting point, considering "the instigatory space of difficulty and not understanding."18 It is an effective conceptual tool for moving a visual art practice into words, for beginning to articulate positions of difficulty; to dwell in those positions and allow writing to be born there.

Trancelation: I call the approach to the uneasy forms of writing across languages and cultures 'trancelation'. It merges trance and transport, it is a state of otherness in motion. It does not seal a text as fixed, approved, legitimate. It transmits despatches from another language or medium and allows it to disturb yet another language or medium. I'm interested in the type of signal that can be broadcast in these flows and transits, through words made present and heard. And in how someone else might pick that signal up and amplify it further. A frequency might meet another and resonate. Misunderstandings, dead ends, and noise reshape the transmission. To interfere with language with languages-where 'research' into literature is not always equal to 'meaning,' 
but questions meanings through rhythms, pauses, breaths, sounds. It does not take the form of a sequence of propositions: it shapes itself through rhythms and inflexions and turns of phrases and words. This is why it demands to be sustained. This is why I go back to it. This writing: discomfortable and unstable; not in translation but 'trancelated' through the material engagement that Jelinek called "what always had to remain unclear and groundless."

[16]

Writing is never only words on paper but all that puts pressure on it nonetheless, that stays unwritten and yet moulds it, its rhythms and tensions; points at bodies, networks, transits, accidents. It makes language impure, not fixed; interferes with what is proper and legitimate; embraces stuttering or language at the level of non-speaking that startles, silences, destabilises. The restless movements of a foreignness from the inside.

\section{[17]}

Working with listening I have developed some reflections around writing and the ephemeral, which in turn inform many conversations with students around the question of the ineffable in art, and how to begin to articulate words nonetheless. Listening: trespassing. Not being confined to a disciplinary reading that clips down — not concerned with the 'about,' listening is verb and method, ${ }^{19}$ and does not exclusively pertain to music and sound. ${ }^{20}$ In the past I have listened to a page, or to a painting: beyond disciplines, groundless in the eyes of given contexts, approaches, references, but not without ground in the writing that holds disparate elements together.

Even at its most implicit, listening has to do with presence-both active and not. It is tied to how knowledge is transmitted, to form another type of knowledge, less depending on hierarchies and quotes, focused on what is passed on, its cadence, its sense before it means. Consider what happened with Clarice [10]: listening to her sigh allowed me to frequent her words more intensely, to hear their pauses with a purposive ear while being distracted from writing. By playing around them in stillness, by staring at them and repeating them, by writing through listening, the "s' of 'Clarice's' possessive was lifted off the page, possessed my words, and prompted more words: listening in writing as research as literature as transmission. 


\section{Endnotes}

1 Elfriede Jelinek, "Sidelined," 2004, https://www.nobelprize.org/nobel_prizes/ literature/laureates/2004/jelinek-lecture-html, date of access: 17 Sept. 2018.

2 Nicoletta Tiliacos, "Fleur dentro un arazzo," in: Il Foglio, 27 Oct. 2014, http://www. ilfoglio.it/articoli/2014/10/27/news/fleur-dentro-un-arazzo-77872/, date of access: 17 Sept. 2018. (Translation: Daniela Cascella.)

3 Alejandra Pizarnik, Extracting the Stone of Madness: Poems 1962-1972, translated by Yvette Siegert. New York, NY: New Directions, 2016, p. 117.

4 Ingeborg Bachmann, Letteratura come utopia (1980), translated by Vanda Perretta. Milano: Adelphi, 2011, p. 123. (English translation from the Italian: Daniela Cascella. For the German original, cf. Probleme zeitgenössischer Dichtung. Frankfurter Vorlesungen. Munich: Piper, 1980.)

5 Bachmann (2011), Letteratura come utopia, p. 109.

6 Bachmann (2011), Letteratura come utopia, p. 120.

7 Bachmann (2011), Letteratura come utopia, p. 123.

8 Bachmann (2011), Letteratura come utopia, p. 109.

9 Bachmann (2011), Letteratura come utopia, p. 25.

10 See also Corina Caduff's consideration around what is articulated 'non-artistically' in "Literature and Artistic Research," in: Corina Caduff et al., eds., Art and Artistic Research, Zurich: Scheidegger \& Spiess, 2010, pp. 98-105.

11 I discussed these concerns in more depth in a public conversation with Kate Briggs at the Society for Artistic Research's 2016 annual conference on Writing in The Hague.

12 Jacques Rancière, The Ignorant Schoolmaster: Five Lessons in Intellectual Emancipation, translated by Kristin Ross. Stanford, CA: Stanford University Press, 1991, p. 67 .

13 Louis Armand, "Language is Never Innocent," 4 June 2017, https://equuspress. wordpress.com/2017/06/o6/language-is-never-innocent/, date of access: 17 Sept. 2018.

14 Clarice Lispector, "Interview," 1977, https://www.youtube.com/watch?v=w1zw GLBpULs, date of access: 17 Sept. 2018.

15 Bhanu Kapil, Ban en Banlieue. New York, NY: Nightboat Books, 2015, p. 42.

16 Kapil (2015), Ban en Banlieue, p. $5^{2}$.

17 Craig Dworkin, No Medium. Cambridge, MA, London: MIT Press, 2015, p. 9.

18 Antena, A Manifesto for Ultratranslation. Houston, TX: Blaffer Museum and Antena Books, 2013, p. 7.

19 Salomé Voegelin, Sonic Possible Worlds: Hearing the Continuum of Sound, New York, NY, London: Bloomsbury, 2014.

20 David Toop, Sinister Resonance: The Mediumship of the Listener, New York, NY, London: Continuum, 2010.

\section{Bibliography}

Antena, A Manifesto for Ultratranslation. Houston, TX: Blaffer Museum and Antena Books, 2013.

Armand, Louis, "Language is Never Innocent," 4June 2017, https://equuspress.wordpress .com/2017/06/o6/language-is-never-innocent/, date of access: 17 Sept. 2018. 
Bachmann, Ingeborg, Letteratura come utopia (1980), translated by Vanda Perretta. Milano: Adelphi, 2011.

Caduff, Corina, "Literature and Artistic Research," in: Corina Caduff et al., eds., Art and Artistic Research. Zurich: Scheidegger \& Spiess, 2010, pp. 98-105.

Dworkin, Craig, No Medium. Cambridge, MA, London: MIT Press, 2015.

Jelinek,Elfriede, “Sidelined," 2004,https://www.nobelprize.org/nobel_prizes/literature/ laureates/2004/jelinek-lecture.html, date of access: 17 Sept. 2018.

Kapil, Bhanu, Ban en Banlieue. New York, NY: Nightboat Books, 2015.

Lispector, Clarice, “Interview," 1977, https://www.youtube.com/watch?v=w1zw GLBpULs, date of access: 17 Sept. 2018.

Pizarnik, Alejandra, Extracting the Stone of Madness: Poems 1962-1972, translated by Yvette Siegert. New York, NY: New Directions, 2016.

Rancière, Jacques, The Ignorant Schoolmaster: Five Lessons in Intellectual Emancipation, translated by Kristin Ross. Stanford, CA: Stanford University Press, 1991.

Tiliacos, Nicoletta, "Fleur dentro un arazzo," in: Il Foglio, 27 Oct. 2014, http://www .ilfoglio.it/articoli/2014/10/27/news/fleur-dentro-un-arazzo-77872/, date of access: 17 Sept. 2018.

Toop, David, Sinister Resonance: The Mediumship of the Listener. New York, NY, London: Continuum, 2010.

Voegelin, Salomé, Sonic Possible Worlds: Hearing the Continuum of Sound. New York, NY, London: Bloomsbury, 2014. 